\title{
Two alternative modes for diffuse pollution control in Wuhan City Zoo
}

\author{
CHEN Qing-feng ${ }^{1,2}$, SHAN Bao-qing ${ }^{1, *}$, YIN Cheng-qing ${ }^{1}$, HU Cheng-xiao ${ }^{2}$ \\ 1. State Key Laboratory of Environmental Aquatic Chemistry, Research Center for Eco-Environmental Sciences, \\ Chinese Academy of Sciences, Beijing 10085, China \\ 2. College of Resources and Environment, Huazhong Agriculture University, Wuhan 430050, China. E-mail: chenqingfeng@webmail.hzau.edu.cn
}

Received 27 December 2006; revised 16 March 2007; accepted 4 April 2007

\begin{abstract}
Pollution in urban zoos arises from diffuse and small point sources. However, its control has received little attention in past decades. Online and offline modes of ecological engineering technology were designed to control pollution from small point and diffuse sources in Wuhan City Zoo, China. Their characteristics and performances were investigated in sixteen runoff events from 2003 to 2005 . The results showed that the two modes both improved runoff water quality and had high retention rates for water and pollutants. In the outflows, the event mean concentrations (EMCs) of total suspended solids (TSS), chemical oxygen demand (COD), total nitrogen (TN) and total phosphorus (TP) were reduced by $88 \%, 59 \%, 46 \%$ and $71 \%$ for the online mode, and those were $77 \%, 42 \%, 50 \%$ and $66 \%$ for the offline mode. The annual retention rates of pollutant loads for the online mode were $94.9 \%-98.5 \%$ in the three study years; those for the offline mode were $70.5 \%-86.4 \%$. Based on calculation, the online mode was able to store the runoff of $66.7 \mathrm{~mm}$ rainfall completely, and the offline mode could store that of $31.3 \mathrm{~mm}$ rainfall. In addition, the online mode can provide an effective way for rainwater utilization and good habitats for aquatic wildlives, and has an excellent aesthetics value for recreationsal pastimes. The offline mode can save land resources and may be an effective and economical measure for diffuse pollution control in urban areas.
\end{abstract}

Key words: eutrophication; runoff; stormwater; wetland; zoo

\section{Introduction}

Pollution in urban zoos arises from both diffuse and small point sources (Zhao et al., 2006). Stormwater runoff is one of the major sources of diffuse pollution. It is responsible for the transport of sediment, nutrients, metals, oils and pesticides (Schreiber et al., 2001; Lazzarotto et al., 2005). Furthermore, stormwater pollution can also have a profound effect on the ecological health of streams and reservoirs (Schreiber et al., 2001; Deletic, 1998) and is one of the main reasons for ecosystem degradation (Yin and Mao, 2002).

The control of diffuse pollution can be divided into online and offline modes based on the runoff route (Bardin et al., 2001; Shan et al., 2006; Paolo et al., 2006). For example, for online mode, all system constructions may be distributed on the runoff route. For offline mode, these constructions may be distributed away from the runoff route. Every mode plays an important role in stabilizing the adjacent ecosystems and reducing the load of runoff pollution. In the process of diffuse pollution control, the selection of the mode is the key step. This choice will be affected by native topography, land uses, and climate. In

Project supported by the Hi-Tech Research and Development Program (863) of China (No. 2002AA601022) and the Hi-Tech Research and Development Program of Tianjin (No. 06FZZDSH00900). *Corresponding author. E-mail: bqshan@rcees.ac.cn. every mode, many ecological engineering techniques can be included. Buffer zones, wetlands, aquatic ecotones and riparian zones, have proved to be effective in removing nutrients from runoff or water bodies (Gilliam, 1994; Patrick, 1995; Mitsch, 1995). However, the application of the two modes in urban zoos has received little research attention.

In this study, two catchments were selected to study the characteristics and performances of the online and offline modes in Wuhan City Zoo, China. For this purpose, an online pond-wetlands system in the Orangutan House Catchment, and an offline filtering ditch-pond system in the Canine House Catchment, were designed to control the small point and diffuse sources of pollution in the zoo. First, runoff water quantity, water quality, pollutant loads and suspended solids of the runoff were investigated for the two modes from 2003 to 2005. Secondly, suggestions regarding selection for the two modes have been considered.

\section{Method and materials}

\subsection{Study site description}

This study was carried out from April 2003 to August 2005 in Wuhan City Zoo, which is surrounded by Moshui Lake. The mean annual temperature in Wuhan City is 
$15.9^{\circ} \mathrm{C}$, and the mean annual precipitation is approximately $1300 \mathrm{~mm}$, of which two-thirds is concentrated from April to August.

Both the Orangutan House Catchment and the Canine House Catchment, which have similar area and a common upland in part, are situated in the northwest of Wuhan City Zoo (Figs.1 and 2). The land use in both catchments mainly includes animal houses, roofs, roads, upland, ponds and wetlands. The animal houses, roofs and roads surfaces are all essentially impervious and account for $20.7 \%$ and $27.9 \%$ of the total area of Orangutan House Catchment and Canine House Catchment, respectively (Table 1). The permeable surfaces, which are divided into many fragments by animal yards, roads, and buildings, include upland, ponds, grasslands and wetlands (Zhao et al., 2006). All the engineering constructions were finished in April 2004.

The soil of Wuhan City Zoo is yellow brown earth and is classified as Quaternary period renewable alluvial clay. Areas of bare surface were common at this zoo prior to 2004. Because of the effect of human activities, large amounts of soil were removed by storm water runoff and this process destroyed the aquatic ecosystems of the Moshui Lake.

In the urban zoo, there were few drainage systems and most of the wastewater and stormwater was discharged directly into Moshui Lake. The coexistence of

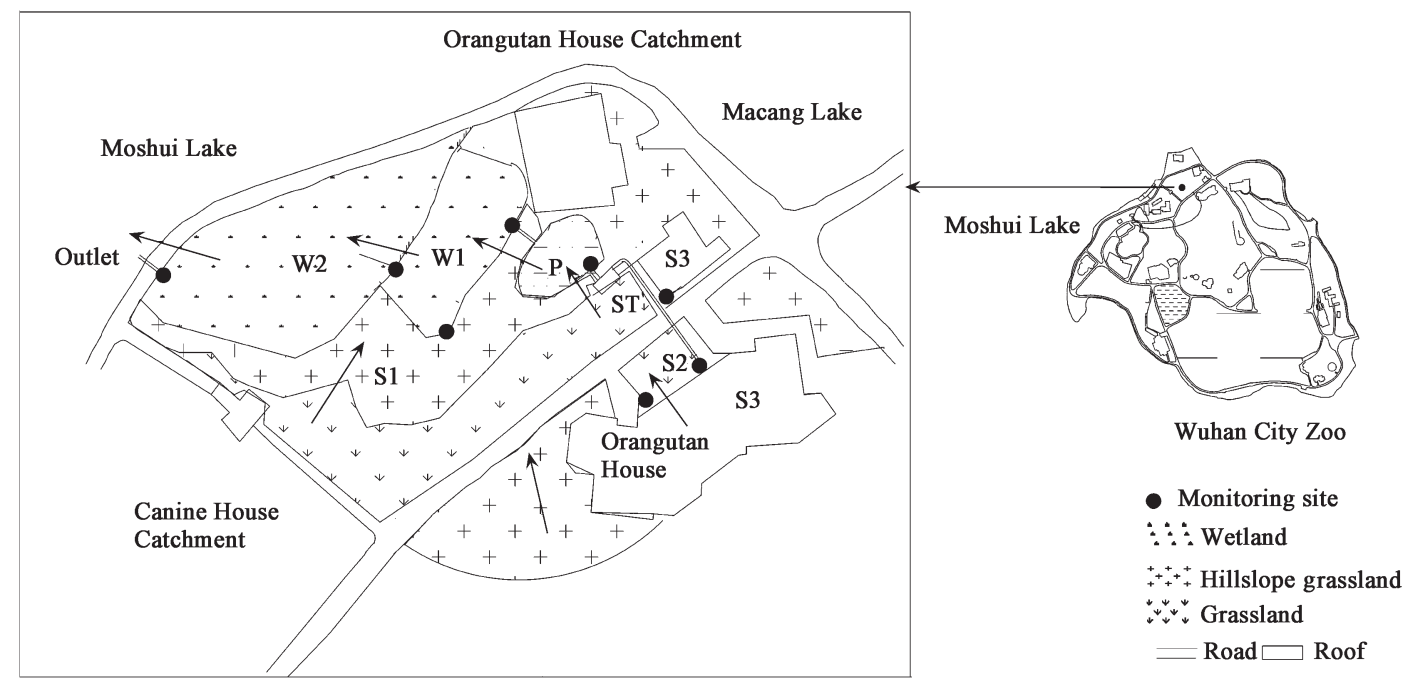

Fig. 1 Location of Orangutan House Catchment and sketch map of the online system. W1: first wetland; W2: second wetland; S1: upland runoff; S2: water flushed from animal houses; S3: roof runoff; P: pond; ST: sediment tank.

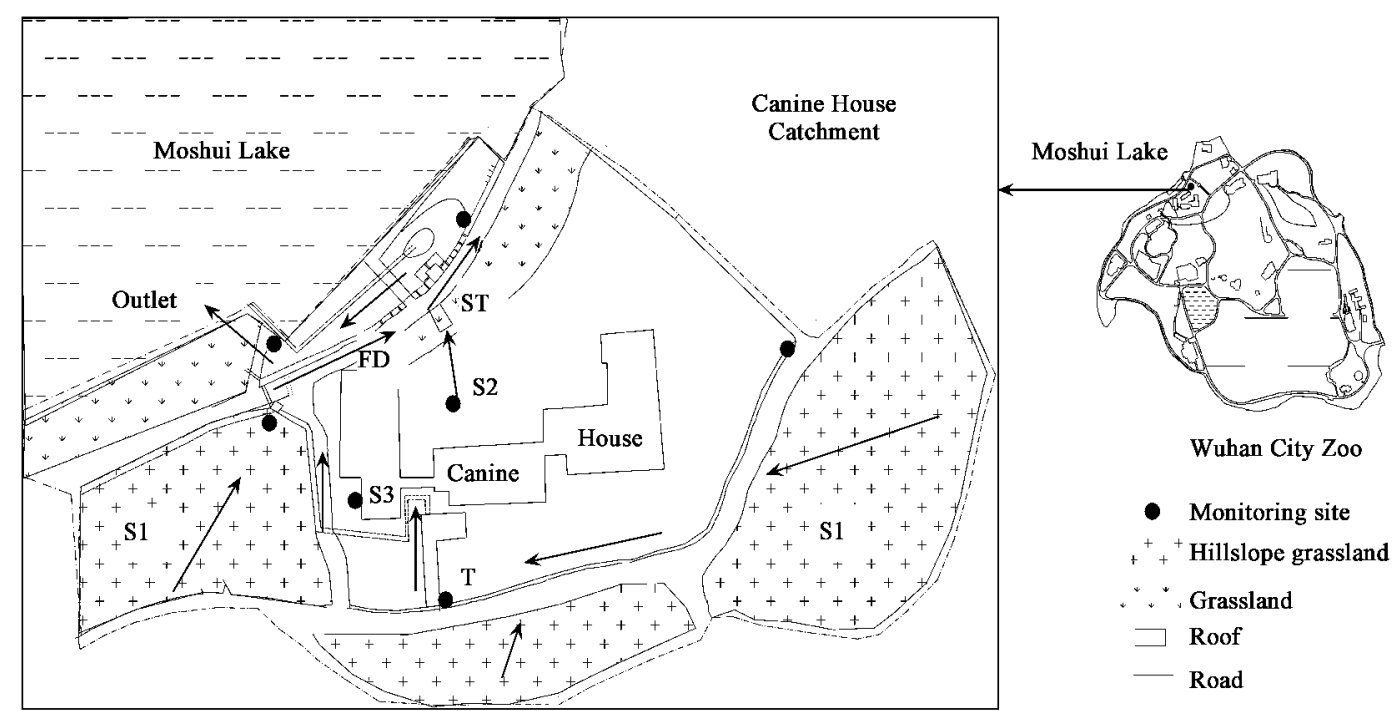

Fig. 2 Location of Canine House Catchment and sketch map of the offline system. FD: filtering ditch; T: storm transport ditch; others are the same as Table 1.

Table 1 Areas of different land uses in the two catchments $\left(\mathrm{m}^{2}\right)$

\begin{tabular}{llllllllr}
\hline Catchment & Upland & Roof & Road & Pond & Wetland & Others & Total & Percentage of impervious area (\%) \\
\hline Orangutan House Catchment & 4874 & 1061 & 754 & 243 & 1704 & 117 & 8753 & 20.7 \\
Canine House Catchment & 5167 & 1578 & 768 & 108 & - & 796 & 8417 & 27.9 \\
\hline
\end{tabular}


both scattered points and diffuse sources pollution was typical. The pollution sources for both catchments were the same, including upland runoff (S1), water flushed from animal houses (S2), and roof runoff (S3). Among the three sources, S2 was a typical point source with consistent amounts of water volume discharged at a scheduled time every day. Generally, S2 was normally stored in a sediment tank (ST) temporally on dry days, and then was discharged with storm water in runoff events. Furthermore, S1 and S3 were diffuse sources with high concentrations of the first runoff and large runoff volume.

\subsection{Two modes description}

In the Orangutan House Catchment, an online pondwetlands system was used to control pollution from small point and diffuse sources. All the engineering constructions were built to adjust the flow rate of storm water and the kinetic energy of runoff on the runoff route. From upland to downstream, the landscape structures included upland grassland, orangutan house, sediment tank (ST), pond $(\mathrm{P})$, the first wetland (W1) and the second wetland (W2). For the huge storage capacity of the pond-wetlands system $\left(1071 \mathrm{~m}^{3}\right)$, most of runoff was able to be stored temporarily and purified by physical, chemical and biologic processes in the wetlands. The online mode flow of the catchment is shown in Fig.3. Through grids, S2 was initially stored in ST on dry days. During rainfall events, all runoff, coming from S1 and S3, as well as S2, flowed through ST, P, W1 and W2 sequentially and then drained into Moshui Lake. In order to save water, the rainwater, stored in the pond-wetlands system, can be reused for flushing the animal house and irrigating the grassland.

Without enough available land area for water treatment constructions, an offline filtering ditch-pond system was designed to control diffuse pollution in the Canine House Catchment. The landscape structures in the catchment include upland grassland, storm transport ditch (T), Canine House, filtering ditch (FD) and ponds (P) from upland to downstream. FD was underground and rebuilt by an old flue, is $83 \mathrm{~m}$ in length, $0.5 \mathrm{~m}$ in width, and $1.2 \mathrm{~m}$

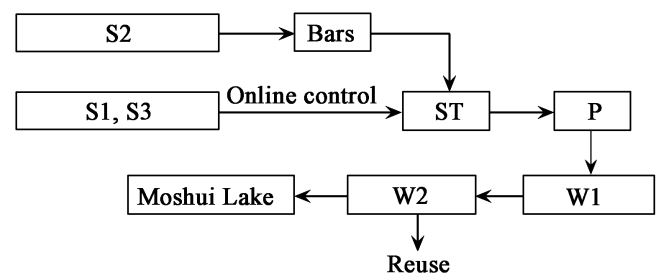

Fig. 3 Online mode for diffuse pollution control in the Orangutan House Catchment. in depth. It has three sections: sediment zone, filtration zone and storage zone. There are 9 subsections in the filtration zone and each subsection is filled with one of the following media: gravel, aluminite stone, bulky sand, cobblestone, ceramic granule, silver sand, turf, steel slag and vermiculite. This offline mode introduced distribution equipment to separate "first flush" from the runoff. Fig.4 shows the offline mode flow. The first runoff was delivered to FD for filtration and adsorption. After that, the runoff overflowed into $\mathrm{P}$ for further decontamination and then, in the final stage, drained into Moshui Lake. With low concentration of pollutants, the later runoff flows through $\mathrm{T}$, bars and is then discharged directly into Moshui Lake.

The selection of the two alternative modes for diffuse pollution control is based on concern with native topography, climate, storm water volume and available land area of the catchment (Fig.5). If there is enough available land area in the catchment, then both modes can be selected. Otherwise, the offline mode may be the only choice for diffuse pollution control. Furthermore, the online mode may be the better choice if reuse of rainwater, additional biologic habitat, and aesthetics value are taken into consideration. In other conditions, the offline mode may be an effective choice for diffuse pollution control.

\subsection{Experimental methods}

Water samples were collected from all the monitoring sites when surface runoff occurred during rainfall events. Water samples were taken every $10 \mathrm{~min}$ in the first 30 min and then at an interval of $30 \mathrm{~min}$ till the end of runoff occurred. Sampling time and runoff volume were recorded simultaneously. Rainfall intensity was recorded by an automated gauge in the zoo. From 2003 to 2005, sixteen runoff events were measured and samples were collected. In the runoff events, the storm event on June 26, $2005 \mathrm{had}$ the highest precipitation $(78 \mathrm{~mm})$. To study the characteristics and control mechanisms of the two alternative modes, this storm event was selected especially for more detailed analyses.

All the samples were analyzed for total nitrogen (TN), dissolved nitrogen (DN), total phosphorus (TP), dissolved phosphorus (DP), total suspended solids (TSS), chemical oxygen demand (COD), conductivity and $\mathrm{pH}$. TSS and COD were measured according to Standard Methods of APHA (1998). All the samples were filtrated through 0.45 $\mu \mathrm{m}$ Millipore filter. The filtrate was used for DN and DP. All the filtered and unfiltered water samples were stored at $4^{\circ} \mathrm{C}$ and analyzed within $48 \mathrm{~h}$ after sampling. Conductivity and $\mathrm{pH}$ were determined with a muti-parameter water quality monitor (YSI model 6600).

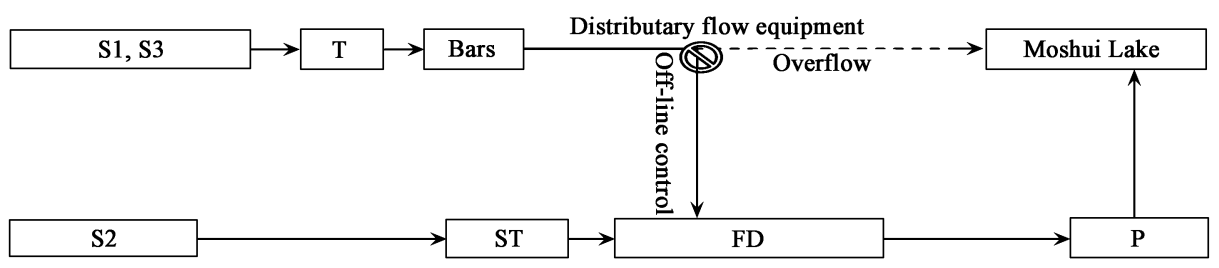

Fig. 4 Offline mode for diffuse pollution control in Canine House Catchment. 


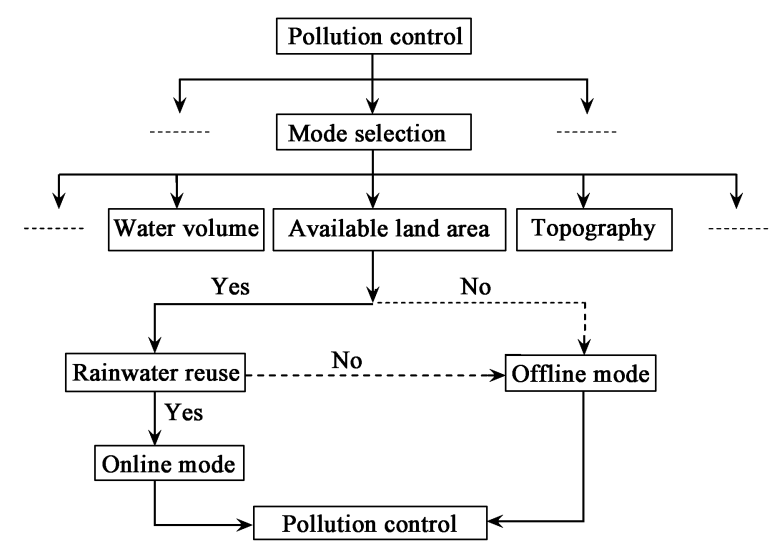

Fig. 5 The flow chart of the two alternative modes selection for diffuse pollution control.

\subsection{Data analyses}

The event mean concentration (EMC) was used to estimate the pollutant load in the runoff (Zhao et al., 2007). The EMC is a flow-weighted average of the constituent concentration. The following equation can be used to calculate this index:

$\mathrm{EMC}=\frac{\int_{0}^{i} C\left(\Delta t_{i}\right) \times Q\left(\Delta t_{i}\right) \mathrm{d} \Delta t_{i}}{\int_{0}^{i} Q\left(\Delta t_{i}\right) \mathrm{d} \Delta t_{i}}$

where, EMC is the event mean concentrations $(\mathrm{mg} / \mathrm{L})$; $C\left(\Delta t_{i}\right)$ is the time variable concentration $(\mathrm{mg} / \mathrm{L}) ; Q\left(\Delta t_{i}\right)$ is the runoff volume discharged at time $t_{i}\left(\mathrm{~m}^{3} / \mathrm{min}\right)$.

The export of pollutants was assessed by the unit pollutant loading rate. The following equation can be used to calculate this index (Lee and Bang, 2000):

$L=K C_{i} \times \Delta Q_{i} \times \Delta t_{i} \times R /\left(\sum \Delta t_{i} \times A_{i} \times I_{i}\right)$

where, $L$ is the unit pollutant loading rate $\left(\mathrm{kg} /\left(\mathrm{hm}^{2} \cdot \mathrm{a}\right)\right.$; $K$ is the conversion constant $\left(10^{-3}\right) ; C_{i}$ is the average concentration of the composite sample during the $\sum \Delta t_{i}$ interval $(\mathrm{mg} / \mathrm{L}) ; \Delta Q_{i}$ is the runoff in $\Delta t_{i}$ interval $\left(\mathrm{m}^{3} / \mathrm{h}\right)$; $\Delta t_{i}$ is the sampling time interval $(\mathrm{h}) ; \sum \Delta t_{i}$ is the rainfall duration (h); $R$ is the annual total rainfall intensity ( $\mathrm{mm} / \mathrm{a})$; $A_{i}$ is the catchment area $\left(\mathrm{hm}^{2}\right) ; I_{i}$ is the rainfall intensity $(\mathrm{mm} / \mathrm{h})$.

The annual total runoff was estimated by annual average runoff coefficient. The following equation can be used to calculate this index:

$C_{v}=1000 \times Q /(A \times R)$

where, $C_{v}$ is the annual average runoff coefficient (no unit); $A$ is the area of catchment $\left(\mathrm{m}^{2}\right) ; Q$ is the annual total runoff $\left(\mathrm{m}^{3}\right) ; R$ is the annual total rainfall intensity (mm/a). According to the balance of water volume, the total output runoff can be expressed as:

$Q_{\mathrm{O}}=Q_{\mathrm{T}}-Q=R \times A \times C_{v} / 1000-\mathrm{Q}$

where, $Q_{\mathrm{O}}$ is the total output runoff $\left(\mathrm{m}^{3}\right) ; Q_{\mathrm{T}}$ is the total runoff $\left(\mathrm{m}^{3}\right) ; Q$ is the capacity of the catchment; $R$ is the rainfall intensity $(\mathrm{mm}) ; C_{v}$ is the runoff coefficient (no unit).

All the data were analyzed by Origin 7.5 and SPSS 11.5 software.

\section{Results}

\subsection{Runoff water quantity characteristics}

In 2003, 2004, and 2005, the annual water (S2) flushed from Orangutan House was $347 \mathrm{~m}^{3}, 290 \mathrm{~m}^{3}$ and $193 \mathrm{~m}^{3}$, respectively, and that of Canine House was $2524 \mathrm{~m}^{3}, 2246$ $\mathrm{m}^{3}$ and $834 \mathrm{~m}^{3}$ (Table 2). The decline of annual water volume mainly resulted from the water-saving measures that had been taken by the zoo. Before 2005, all the animal waste on the surfaces of animal yards was flushed directly by water. In 2005 , brooms were used initially to sweep animal waste. Then, water was used to flush the yards. This procedure results in large water savings.

From 2003 to 2005, the annual input water volume in the two catchments decreased gradually (Table 2). This is possibly related to improvement in surface conditions. Before the ecological engineering project started in 2003, the soil was of poor penetrability, and the runoff water volume was the largest during the three-year monitoring period. However, the export runoff was not monitored. After the project was finished in April 2004, an ecological engineering system gradually came into use for control of runoff pollution. In 2004, the retention rate of annual runoff volume for the online mode accounted for approximately $95.1 \%$ and that for the offline mode accounted for approximately $71.1 \%$. In 2005 , there was no significant difference of the retention rate compared to that in 2004 for the two modes $(p>0.05)$.

During the storm event on June 26, 2005, S1 and S3 were the main sources of storm water, generated from the two catchments (Fig.6). Approximately $30 \mathrm{~m}^{3}$ of the runoff from Orangutan House Catchment entered the Moshui Lake from the outlet of W2. As for offline mode, the runoff from Canine House Catchment in the outlet of $\mathrm{P}$ was approximately $78 \mathrm{~m}^{3}$.

In addition, the storage capacity of the online pondwetlands system is about $1071 \mathrm{~m}^{3}$, which is greater than that of offline filtering ditch-pond system $\left(115 \mathrm{~m}^{3}\right)$. According to Equations 3 and 4, the online pond-wetlands

Table 2 Hydrologic budgets of the two catchments from 2003 to 2005

\begin{tabular}{|c|c|c|c|c|c|c|c|c|c|}
\hline \multirow[t]{2}{*}{ Year } & \multicolumn{4}{|c|}{ Orangutan House Catchment $\left(\mathrm{m}^{3}\right)$} & \multicolumn{4}{|c|}{ Canine House Catchment $\left(\mathrm{m}^{3}\right)$} & \multirow{2}{*}{$\begin{array}{l}\text { Rainfall } \\
(\mathrm{mm})\end{array}$} \\
\hline & S2 & Input & Output & Retention & S2 & Input & Output & Retention & \\
\hline 2003 & 347 & 9196 & - & - & 2524 & 10516 & - & - & 1356 \\
\hline 2004 & 290 & 7871 & 389 & $95.1 \%$ & 2246 & 9828 & 2841 & $71.1 \%$ & 1497 \\
\hline 2005 & 193 & 6122 & 292 & $95.2 \%$ & 834 & 6783 & 1348 & $80.1 \%$ & 1300 \\
\hline
\end{tabular}



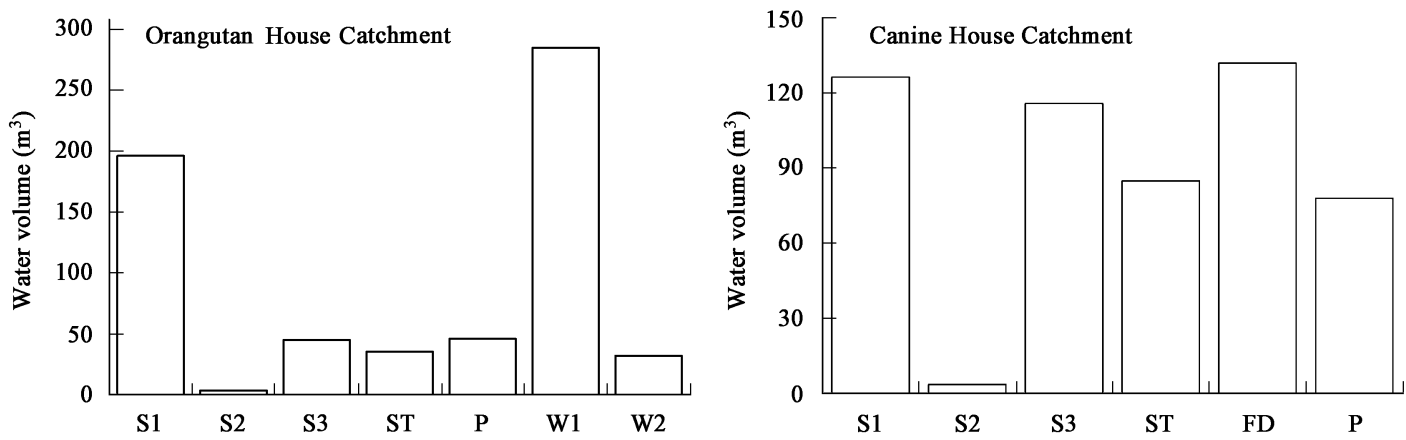

Fig. 6 Water volume in system structures of the two catchments on June 26, 2005 storm event. S1, S2, S3 are the main sources of storm water.

system was able to store the runoff of $66.7 \mathrm{~mm}$ rainfall completely, and the offline filtering ditch-pond system could store that of $31.3 \mathrm{~mm}$ rainfall.

\subsection{Runoff water quality characteristics}

During the three years, sixteen runoff events were investigated in the two catchments. Water quality analyses (Table 3) indicated that the two control modes were both capable of improving the quality of runoff. In the inflows, the EMCs of TSS, COD, TN and TP were 378, 140, 11.0 and $1.98 \mathrm{mg} / \mathrm{L}$ for online mode, and those were 197, 75, 11.5 and $1.82 \mathrm{mg} / \mathrm{L}$ for offline mode. In the outflows, the EMCs of TSS, COD, TN and TP were reduced by $88 \%$, $59 \%, 46 \%$ and $71 \%$ than the inflows for online mode, and those were $77 \%, 42 \%, 50 \%$ and $66 \%$ for offline mode. There was no difference between the outflows of the two modes $(p>0.05)$. For all the pollutant sources, S1 was the main source of the runoff and the order of EMC was in the flowing: $\mathrm{S} 1>\mathrm{S} 2>\mathrm{S} 3$. .

In the export system, conductivity was significantly higher than in the input runoff for the two modes $(p<$ 0.01 ) (Table 3). Outflow $\mathrm{pH}$ values were $\mathrm{pH} 7.04 \pm 0.23$ and $7.35 \pm 0.17$ for the online mode and the offline mode, respectively. Contrasted with inflow $\mathrm{pH}$ values, outflow $\mathrm{pH}$ values were closer to neutral.

\subsection{Pollutant loads characteristics in runoff}

Analyses (Table 4) showed that the annual retention rate of pollutant loads for the online mode was $94.9 \%-$ $98.5 \%$ and that for the offline mode was $70.5 \%-86.4 \%$ in the two years. In 2003, the average annual inputs loads of TSS, COD, TN and TP were approximately 11112, $3235.4,333.4$, and $25.48 \mathrm{~kg} / \mathrm{hm}^{2}$, respectively. In 2004 , the pollutant loads decreased by $65 \%$ of TSS, $25 \%$ of COD,

Table 3 EMCs of the pollutants in the two catchments for sixteen runoff events

\begin{tabular}{|c|c|c|c|c|c|}
\hline \multirow[t]{2}{*}{ Index } & \multicolumn{4}{|c|}{ System input } & \multirow{2}{*}{$\begin{array}{l}\text { System export } \\
(\text { mean } \pm \mathrm{SD})\end{array}$} \\
\hline & $\mathrm{S} 1($ mean $\pm \mathrm{SD})$ & $\mathrm{S} 2($ mean $\pm \mathrm{SD})$ & $\mathrm{S} 3($ mean $\pm \mathrm{SD})$ & Average of $\mathrm{S} 1+\mathrm{S} 2+\mathrm{S} 3$ & \\
\hline \multicolumn{6}{|c|}{ Orangutan House Catchment (online mode) } \\
\hline TSS (mg/L) & $950 \pm 143$ & $131 \pm 275$ & $53 \pm 43$ & 378 & $46 \pm 28$ \\
\hline $\mathrm{COD}(\mathrm{mg} / \mathrm{L})$ & $274.6 \pm 75.1$ & $93.5 \pm 237.9$ & $51.7 \pm 69.9$ & 140 & $57.4 \pm 41.2$ \\
\hline $\mathrm{TN}(\mathrm{mg} / \mathrm{L})$ & $12.7 \pm 6.58$ & $9.4 \pm 26.7$ & $11.0 \pm 6.5$ & 11.0 & $5.9 \pm 3.5$ \\
\hline $\mathrm{TP}(\mathrm{mg} / \mathrm{L})$ & $2.64 \pm 1.76$ & $2.34 \pm 2.75$ & $0.97 \pm 0.58$ & 1.98 & $0.58 \pm 0.26$ \\
\hline Conductivity (mS/cm) & $0.129 \pm 0.042$ & $0.234 \pm 0.028$ & $0.175 \pm 0.57$ & 0.179 & $0.286 \pm 0.085$ \\
\hline $\mathrm{pH}$ & $7.22 \pm 0.14$ & $6.98 \pm 0.035$ & $6.27 \pm 0.28$ & 6.82 & $7.04 \pm 0.23$ \\
\hline \multicolumn{6}{|c|}{ Canine House Catchment (offline mode) } \\
\hline TSS (mg/L) & $307 \pm 115$ & $203 \pm 225$ & $82 \pm 34$ & 197 & $45 \pm 24$ \\
\hline $\mathrm{COD}(\mathrm{mg} / \mathrm{L})$ & $117.6 \pm 59.2$ & $47.1 \pm 175$ & $59.7 \pm 12.7$ & 75 & $43.7 \pm 34.1$ \\
\hline $\mathrm{TN}(\mathrm{mg} / \mathrm{L})$ & $16.7 \pm 5.07$ & $9.8 \pm 15.6$ & $7.9 \pm 2.1$ & 11.5 & $5.7 \pm 2.8$ \\
\hline $\mathrm{TP}(\mathrm{mg} / \mathrm{L})$ & $2.15 \pm 1.28$ & $2.48 \pm 2.15$ & $0.83 \pm 0.73$ & 1.82 & $0.61 \pm 0.75$ \\
\hline Conductivity (mS/cm ) & $0.142 \pm 0.047$ & $0.34 \pm 0.025$ & $0.097 \pm 0.012$ & 0.193 & $0.345 \pm 0.12$ \\
\hline $\mathrm{pH}$ & $7.01 \pm 0.18$ & $7.74 \pm 0.045$ & $7.59 \pm 0.17$ & 7.45 & $7.35 \pm 0.17$ \\
\hline
\end{tabular}

Table 4 Retention rates of annual pollutant loads by the two modes in both catchments during three years

\begin{tabular}{|c|c|c|c|c|c|c|c|c|c|}
\hline \multirow[t]{2}{*}{ Index } & \multicolumn{3}{|c|}{ Annual input $\left(\mathrm{kg} /\left(\mathrm{hm}^{2} \cdot \mathrm{a}\right)\right)$} & \multicolumn{3}{|c|}{ Annual output $\left(\mathrm{kg} /\left(\mathrm{hm}^{2} \cdot \mathrm{a}\right)\right)$} & \multicolumn{3}{|c|}{ Retention $(\%)$} \\
\hline & 2003 & 2004 & 2005 & 2003 & 2004 & 2005 & 2003 & 2004 & 2005 \\
\hline \multicolumn{10}{|c|}{ Orangutan House Catchment (online mode) } \\
\hline TSS & 11585 & 4382 & 2739 & - & 174 & 51 & - & 96.0 & 98.2 \\
\hline COD & 3682.2 & 2957.4 & 1437.2 & - & 44.2 & 32.2 & - & 98.5 & 97.8 \\
\hline $\mathrm{TN}$ & 281.7 & 198.1 & 138.1 & - & 5.7 & 2.9 & - & 97.1 & 97.9 \\
\hline $\mathrm{TP}$ & 22.17 & 15.94 & 12.20 & - & 0.81 & 0.24 & - & 94.9 & 98.0 \\
\hline \multicolumn{10}{|c|}{ Canine House Catchment (offline mode) } \\
\hline TSS & 10639 & 3423 & 1669 & - & 464 & 226 & - & 86.4 & 86.4 \\
\hline COD & 2788.5 & 1895.8 & 1520.9 & - & 559.4 & 221.1 & - & 70.5 & 85.5 \\
\hline $\mathrm{TN}$ & 385.1 & 277.8 & 181.7 & - & 44.6 & 29.3 & - & 83.9 & 83.9 \\
\hline $\mathrm{TP}$ & 28.79 & 24.54 & 18.05 & - & 4.99 & 3.08 & - & 79.6 & 82.9 \\
\hline
\end{tabular}


$28 \%$ of TN and $22 \%$ of TP. Because of lower precipitation and the gradual restoration of the two catchments ecosystems, the retention rates of TSS, COD, TN, TP for the online mode accounted for $98.2 \%, 97.8 \%, 97.9 \%$ and $98.0 \%$, respectively and those for the offline mode accounted for $86.4 \%, 85.5 \%, 83.9 \%$ and $82.9 \%$ in 2005 . Li (2006) reported that $48 \%, 67 \%, 78 \%$ of the TSS load was transported in the first $5 \mathrm{~mm}, 10 \mathrm{~mm}$ and $15 \mathrm{~mm}$ runoff depth, respectively. Possibly, these high retention rates may be related to the control of the first runoff and the difference in the retention mechanism of the two modes.

The annual pollutant loads of TSS and COD, generated from the Orangutan House Catchment, were higher than those from the Canine House Catchment. On the other hand, the annual pollutant loads of TN and TP, generated from Canine House Catchment, were higher than those from Orangutan House Catchment. This was probably due to the steeper upland in the Orangutan House Catchment and the larger water volume of S2 in Canine House Catchment.

\subsection{Suspended solids characteristics in runoff}

The particulate nitrogen $(\mathrm{PN})$ and phosphorus $(\mathrm{PP})$ were mainly in the form of nitrogen and phosphorus in runoff of the two catchments (Fig.7). The variation range of PN\% was $40 \%-85 \%$, and that of PP\% was $34 \%-98 \%$ in different system structures of the two modes. In the two catchments, the percentages of PP in the three sources differed. S1 had the largest percentage of PP, and the order of the percentages was $\mathrm{S} 1>\mathrm{S} 2>\mathrm{S} 3$. In Orangutan House Catchment and Canine House Catchment inflows, the percentage of PN was approximately $81 \%$ and $69 \%$, and that of PP was approximately $89 \%$ and $90 \%$, respectively. In the outflows, the percentage of PN and PP was approximately $60 \%$ and was not significantly different between the two modes ( $p$ $>0.05)$. Therefore, both of the modes were effective in reducing particulate matters in runoff.

In Orangutan House Catchment inflows, the average grain size of suspended solid from S1, S2 and S3 was approximately 310,220 and $120 \mu \mathrm{m}$, respectively, and that for Canine House Catchment was approximately 250, 200 and $110 \mu \mathrm{m}$ (Fig.8), which could be classified as fine sands (Cahoon et al., 1999). In the outflows, the grain size of particulate matters both reduced to $20 \mu \mathrm{m}$ (silt and clay). Therefore, the two modes can both reduce the grain size of suspended solids from fine sands to silt and clay in runoff. For the online mode, the explanation is possibly due to the long retention time and the physical sedimentation of the pond-wetlands system. For the offline mode, the explanation is possibly related to the filtration of media in the filtering ditch-pond system.

\section{Discussion}

For the online mode, the retention mechanism is probably due to the long retention time and the physical, chemical and biologic functions (Fennessy et al., 1994) of the pond-wetlands system. This mode can control runoff pollution, and also can store considerable rainwater in runoff events. This stored water can then be reused for flushing the animal house, improving local climate, and irrigating the grassland.

On the other hand, the online mode also was able to provide additional habitat for aquatic biology, and excellent aesthetic value for recreational pastimes. For the
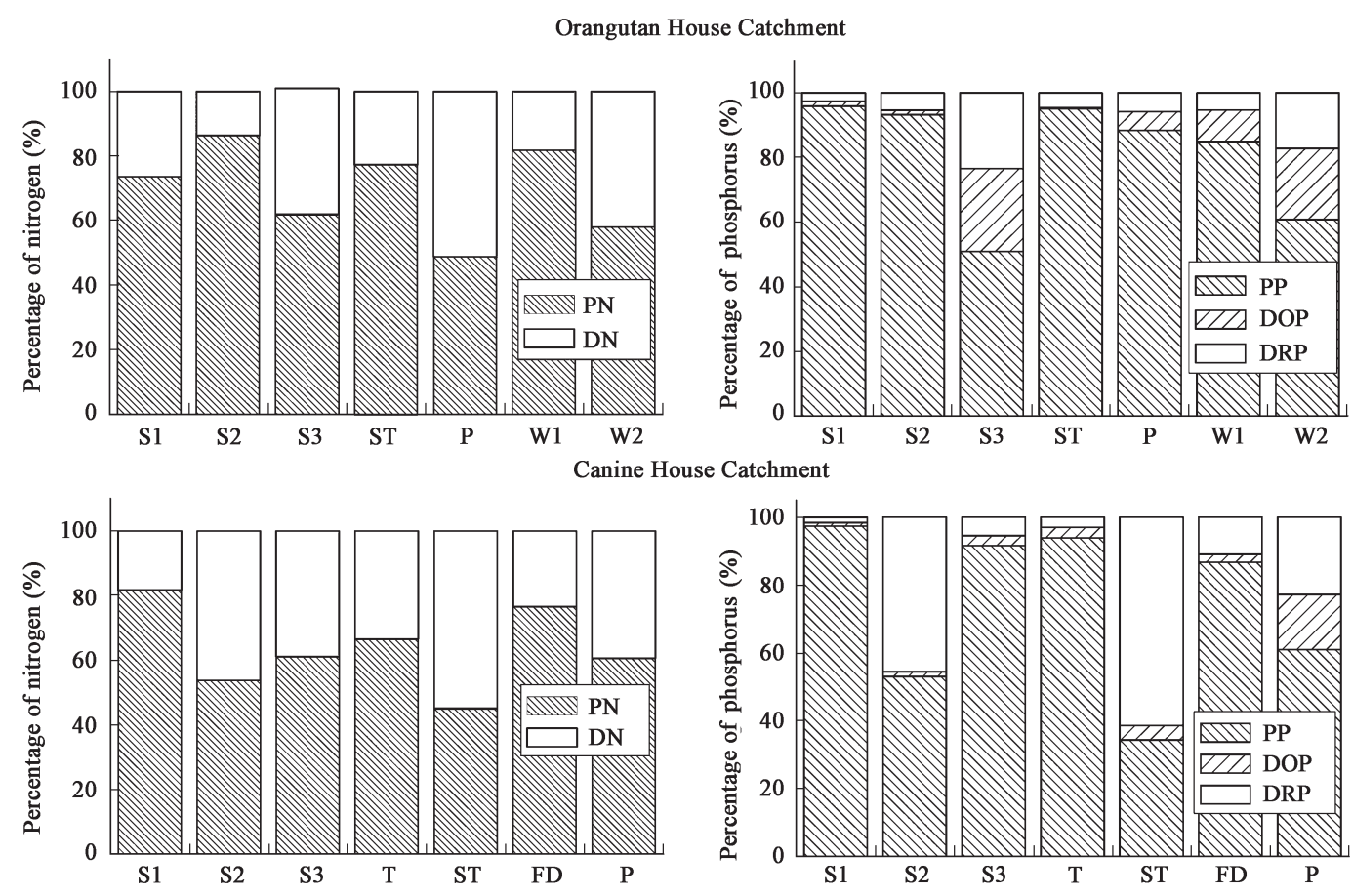

Fig. 7 Percentage of particulate nitrogen and phosphorus in the two catchments. PN: particulate nitrogen; DN: dissolved nitrogen; PP: particulate phosphorus; DP: dissolved phosphorus; DRP: dissolved reactive phosphorus. PN and PP concentrations were determined as the difference between TN and DN, and that between TP and DP, respectively. S1, S2, S3 are the main sources of storm water. 

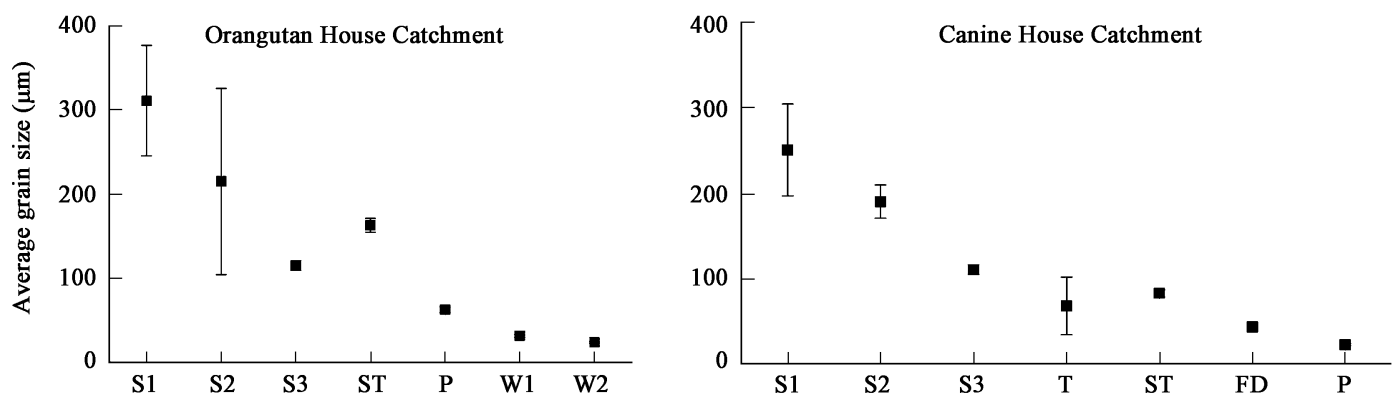

Fig. 8 Change of average grain size of suspended solids in the two catchments. S1, S2, S3 are the main sources of storm water.

offline mode, the retention mechanism was due to the adsorption and filtration functions of substrate materials in the filtering ditch-pond system. Considering economic factors, the offline filtering-ditch ponds system occupies only $1.68 \%$ of the total area of the catchment, requires a lower cost for construction, works by a natural process, and requires no power for maintenance. Therefore, the offline mode may be an effective and economical measure for diffuse pollution control in urban areas.

\section{Conclusions}

The online and offline modes are both able to improve the quality of runoff water, reduce the grain size of suspended solids from fine sands to silt and clay, and have high retention rates of the runoff pollutant loads. The online mode may be better adapted to urban zoos, suburbs and towns that have abundant available land area. On the other hand, the offline mode can save land resources and is more effective and economical for diffuse pollution control in urban areas, such as industrial and residential areas.

The contrast between the online and the offline modes in this study was as follows: In the outflows, the EMCs of TSS, COD, TN and TP were reduced by $88 \%, 59 \%, 46 \%$ and $71 \%$ for the online mode, and those were $77 \%, 42 \%$, $50 \%$ and $66 \%$ for the offline mode. The annual retention rates of pollutant loads for the online mode was $94.9 \%-$ $98.5 \%$ and that for the offline mode was $70.5 \%-86.4 \%$ over a three year period. Calculations indicated that the online mode could store the runoff of $66.7 \mathrm{~mm}$ rainfall completely, and the offline mode could store the runoff of $31.3 \mathrm{~mm}$ rainfall.

\section{Acknowledgements}

The authors thank Dr. A. Honig and Dr. Hong J. Di for English corrections of the manuscript.

\section{References}

Bardin J P, Barraud S, Chocat B, 2001. Uncertainty in measuring the event pollutant removal performance of online detention tanks with permanent outflow[J]. Urban Water, 3: 91-106.

Cahoon L B, Nearhoof J E, Tilton C L, 1999. Sediment grain size effect on benthic microalgal biomass in shallow aquatic ecosystems[J]. Estuarines, 22(3B): 735-741.
Deletic A, 1998. The first flush load of urban surface runoff[J]. Water Research, 32(8): 2462-2470.

Fennessy M S, Brueske C C, Mitsch W J, 1994. Sediment deposition patterns in restored freshwater wetlands using sediment traps[J]. Ecological Engineering, 3: 409-428.

Gilliam J W, 1994. Riparian wetlands and water quality[J]. Journal of Environmental Quality, 23: 896-900.

Haygarth P M, Wood F L, Heathwaite A L et al., 2005. Phosphorus dynamics observed through increasing scales in a nested headwater-to-river channel study[J]. Science of the Total Environment, 344: 83-106.

Lazzarotto P, Prasuhn V, Butscher E et al., 2005. Phosphorus export dynamics from two Swiss grassland catchments[J]. Journal of Hydrology, 304: 139-150.

Lee J H, Bang K W, 2000. Characterization of urban stormwater runoff[J]. Water Research, 34(6) : 1773-1780.

Li L Q, Yin C Q, HE Q C et al., 2006. Catchment-scale pollution process and first flush of urban storm runoff in Hanyang, Wuhan City[J]. Acta Scientiae Circumstantiae, 26(7): 1057-1061.

Michael J H, 2003. Nutrients in salmon hatchery wastewater and its removal through the use of a wetland constructed to treat off-line setting pond effluent[J]. Aquaculture, 226: 213-225.

Mitsch W J, 1995. Restoration of our lakes and rivers with wetlands: an important application of ecological engineering[J]. Water Science and Technology, 31: 167-177.

Paolo S C, Gaspare V, 2006. Simulation of the operation of detention tanks[J]. Water Research, 40(1): 83-90.

Patrick R, 1995. Rivers of the United States, Volume II: Chemical and physical characteristics[M]. New York: Willey.

Schreiber J D, Rebich R A, Cooper C M, 2001. Dynamics of diffuse pollution from us southern catchments[J]. Water Research, 35(10): 2534-2542.

Shan B Q, Chen Q F, Yin C Q, 2006. On-line control of stormwater pollution by pond-wetlands composite system in urban tourist area[J]. Acta Scientiae Circumstantiae, 26(7): 1068-1075.

Yin C Q, Mao Z P, 2002. Nonpoint pollution control for rural areas of China with ecological engineering technologies[J]. Chin J Appl Ecol, 13(2): 229-232.

Zhao J W, Shan B Q, Yin C Q, 2006. Characterization of stormwater pollution in urban tourist attractions- A case study in Wuhan Zoo[J]. Acta Scientiae Circumstantiae, 26(7): 10621067.

Zhao J W, Shan B Q, Yin C Q, 2007. Pollutant loads of surface runoff in Wuhan City Zoo, an urban tourist area[J]. Journal of Environmental Sciences, 19(4): 464-468. 